\title{
Analysis of the Impressions before and after Appreciation of Japanese, Chinese and Korean Traditional Dance Based on Text Mining
}

\author{
Hongjie Zheng1* ${ }^{*}$ Shogo Komatsu², Koichiro Aoki², Chieko Kato ${ }^{2}$ \\ ${ }^{1}$ Faculty of Science and Engineering, Toyo University, Kawagoe, Japan \\ ${ }^{2}$ Faculty of Information Sciences and Arts, Toyo University, Kawagoe, Japan \\ Email: *tei@toyo.jp
}

How to cite this paper: Zheng, H., Komatsu, S., Aoki, K., \& Kato, C. (2020). Analysis of the Impressions before and after Appreciation of Japanese, Chinese and Korean Traditional Dance Based on Text Mining. Psychology, 11, 845-864.

https://doi.org/10.4236/psych.2020.116055

Received: May 6, 2020

Accepted: June 1, 2020

Published: June 4, 2020

Copyright () 2020 by author(s) and Scientific Research Publishing Inc. This work is licensed under the Creative Commons Attribution International License (CC BY 4.0).

http://creativecommons.org/licenses/by/4.0/

\begin{abstract}
It is great significance from the perspective of different cultural exchanges to grasp the psychological impact of literature, art, and dance in various countries and to clarify their common points and differences. Therefore, this study takes the traditional performing arts and dances of Japan, China, and South Korea as the research object to explore the psychological changes brought by these performing arts and dances. To analyze the psychological changes before and after appreciation in the free description part of the questionnaire, we use the free software Word Clouds and $\mathrm{KH}$ coder to conduct a quantitative analysis of the text. Based on the word appearance frequency, the analysis combines a variety of analysis methods such as word cloud, co-occurrence network, self-organization map. By confirming the original data and explaining the visualization results, this paper expounds on the relationship between the characteristics of performing arts and dances in different countries and the psychological influence of audiences.
\end{abstract}

\section{Keywords}

Traditional Dance, Questionnaire Survey, Text Mining, Word Clouds, KH Coder

\section{Introduction}

Dance is an art activity composed of various body movements and dancers communicate specific intentions and emotions to spectators through their rhythmic movement. The dancers can express themselves through body movements while the spectators can sympathize with and understand them, in terms of which dance has the aspect of non-verbal communication. The study by Sawada 
et al. (2003) focusing on relationships between emotional expression and characteristics of dance movement reported that expressions of joy, grief, and anger have different movement characteristics and observers could distinguish these emotions expressed through the movement. In this way, dancers can express their emotions and spectators can understand the expressions through the dance movement based on the assumption that specific movements can be associated with specific emotions. It is important for the dancers to convey their emotions, beliefs, and values in body movement properly to spectators as well as quality of dance performance. Therefore, the dancers need to understand what information various dance movements and combinations of them convey to the spectators in order to facilitate non-verbal communication between them. Understanding such psychological effects of body expressions is important also for learning dance skills and creation of dance routines. Because of that many studies have been conducted focusing on the emotions which are expressed and conveyed through dance movement from the viewpoints of dance spectators.

Matsumoto (1987) proposed the seven kinds of dance movement (seven motives) as the minimum units of body expression in dance. Matsumoto named each movement as "natural", "happy", "lonely", "sharp", "solemn", "dynamic", and "flowing" based on the impressions spectators received from the dance movement. The study by Sakata et al. (2002), which conducted impression evaluation on body expression and analysis of observers' gaze, showed that when the observers received specific impressions through watching seven motives they tended to focus on space around the dancer's body (space surrounded by the body, center point of the body area, extension lines of the body parts, and so on). Shikanai et al. (2013) also carried out evaluation of impression and motion characteristics of dance movement expressing emotions of joy, grief, and anger. They obtained three factors of impression and four factors of movement based on the results of evaluation and constructed a model about the relationship between each emotion, impression, and movement. These previous studies suggested that impression formation on various dance works, in which each body movement and its motion characteristics play an important role, has a common tendency.

Although specific body movement is related to expression, traditional dances in each country adopt various styles of expression which are associated with different beliefs and values respectively. Mito et al. $(2007,2008)$ conducted evaluation of impression on gestures of five styles of classical Japanese dances and examined the relationship between the evaluation by spectators and measured values of these movements by motion capture system. The results of their study showed that speed, change and stability of the movements have influences on the spectators' impressions such as "clarity", which became stronger as rotation speed of the upper body increases, and "aesthetic", which became stronger as the speed decreases. In particular, they reported that features of each dance style were reflected in the forms of the dancers' body, direction of movements, and 
forcefulness of them. Chinese traditional dances require rounded and circular motions, stillness and movement, contrast of hardness and softness, and precise rhythms and movements as peculiar aesthetic principles (Fu, 1997). The rounded and circular motions are particularly contrasted with western dances such as ballet which requires linear motions (Yue, 2017). Korean traditional dances are based on Tai Chi (Great Absolute), the idea that all phenomena are divided into yin and yang and they alternate cyclically. This is reflected in characteristics such that the dance ends where it begins after alternating circling movements, advancing and retreating (Yoo, 2007). Based on such cultural differences, there can be differences in characteristics of movement between traditional dances even in the case where dancers convey the same emotions to spectators.

Body movement is interpreted as self-expression of various cultural backgrounds in conjunction with others (Nyström \& Lauritzen, 2005). Therefore, consideration of cultural and social backgrounds of both dancers and spectators is necessary to understand meaning and function of body expression in traditional dances. According to the study by Camurri et al. (2003), emotional expression of grief is recognized by observers more precisely than emotional expression of fear. Meaning conveyed through body movement by dancers necessarily corresponds with impression received by spectators. Studies focusing on characteristics of spectators' recognition is required for clarification of the impression traditional dances give them.

If investigation of impression and cross-cultural comparison clarified common points and differences of traditional dances between various countries, it leads to defining parts of each body expression in non-verbal communication. Results of these studies are expected to contribute to creative activities by dancers. Previous studies in various fields reported their results regarding cross-cultural studies on dances in countries around the world (e.g., Kinjo, 1973). However, as for impression dances give to spectators, quantitative study and data analysis is necessary for accumulation of objective knowledge. The results of studies regarding cross-cultural comparison, in particular, can be utilized for cross-cultural communication through body movement in dance, which is meaningful also from the viewpoint of promoting cross-cultural understanding.

Questionnaires using psychological scales were mainly conducted for impression evaluation of dance works. Recently, there were some studies which focused on appreciation of paintings (Tanaka, 2018; Tadaki \& Abe, 2019) and ballet (Daigo et al., 2019), evaluation of rhythm of dance (Santos et al., 2018), and online review for movies (Swierczynska-Kaczor \& Wachowicz, 2017) analyzed spectators, instructors, and users' thoughts by text mining their opinions and descriptions. For instance, Tadaki \& Abe (2019) verified the effects of creating story about abstract art works on appreciation of them. This study analyzed participants' free descriptions about art appreciation by free software $\mathrm{KH}$ Coder (Higuchi, 2016; Higuchi, 2017) for text mining and calculated appearance fre- 
quency of each word extracted from the descriptions. Correspondence analysis was also performed based on the appearance frequency data and the results of analysis showed the existence of bold line in the artworks is an important factor for creating a story. Santos et al. (2018) developed a system for evaluation of dancers' rhythm based on their acceleration data and compared the results of evaluation by this system with the results of experts' evaluation. This study extracted keywords from experts' comments using TF-IDF as a text mining method and classified the keywords into six themes. In addition, they showed that synchronicity, that is, synchronizing one's movement with music, is an important aspect for evaluation of rhythm in dance by calculating ratios of each theme accounting for the experts' comments. Although the analysis of the psychological process through art appreciation and the evaluation of rhythm in dance tended to be influenced by participants or experimenters' subjectivity, these studies realized objective analysis by means of text mining.

It is essential to refer to spectators' data such as opinions and descriptions in which their inner world is deeply reflected for grasping contents and transition of one's thoughts and emotion evoked by art works in detail. However, sharing results of evaluation on art works and expression is difficult for experts and non-experts because the evaluation requires professional skills. Text mining enables them to analyze the results of evaluation quantitatively and objectively and creates knowledge which can be utilized widely regardless of expertise. Analysis of the spectators' opinions and descriptions is expected to clarify their psychological process through appreciation of traditional dances in detail for verification of psychological effects of these art works.

This study focused on Japanese, Chinese, and Korean traditional dances and conducted a survey on impressions and mental states brought by appreciation of these dances. Participants of this study were asked to answer open-ended questions related to their impressions and mental states after they observed and appreciated the dances on the internet. The responses were quantitatively analyzed by means of text mining and the impressions and mental states represented in words were visualized and interpreted. Characteristics of dances in each country and their psychological effects on the spectators are clarified through the above analysis.

\section{Research Methods}

\subsection{Application of Text Mining Technology}

Text mining (Berry, 2004), also known as text data mining, is a technology that takes text data as the analysis object and is processed and analyzed by the computer. Using text mining technology, we can get valuable information and knowledge from text data. In recent years, text mining technology has been widely used in enterprise management, economy, medical and other fields.

Using Google scholars to search for documents with the keywords of "text mining", the research on "medical and life sciences" ranks high in both Japanese 
and English literature (Fujii, 2017). Such as, text mining is used for analyzing on the questionnaire about the safety of drug (Kimura et al., 2005), analyzing the actual incident reports to prevent medical accidents in hospitals (Okabe et al., 2006), and extracting clinical course knowledge from medical documents, which are written in natural language (Abe et al., 2007). It is also applied to nursing records (Chang et al., 2019) and electronic hospital records (Simon et al., 2016).

Also, new knowledge can be acquired automatically from massive text data by using big data on the Internet. For example, in the field of business, there are posts on bulletin boards, personal blogs, and online shopping goods on the Internet. Furthermore, product survey can let a company learn what their users think about their products. Text mining is used as a powerful method to understand the needs of consumers. A framework of applying online product reviews to analyze customer preferences for two competitive products can be found in (Wang et al., 2018).

Moreover, textbook mining technology is also used for university education and training. For example, a questionnaire survey was conducted among college PE students to investigate the subjective benefits of College PE (Nishida et al., 2015). Park et al. (2017) using the method of text mining to analyze the dance images held by college students who choose dance courses.

In dance research, most researchers focus on body movement and dance arrangements (Tsukamoto et al., 2003; Tsuruta et al., 2009). However, it is rarely discussed from the perspective of the audience. In this study, we explore the psychological changes caused by dance appreciation from the perspective of the audience. The target analysis dances are traditional dances of Japan, China, and South Korea.

\subsection{Text Mining Process}

Steps of the basic text mining process are depicted in Figure 1. Text mining usually involves the text data collection, text pre-processing (e.g., synonym replacement, word segmentation), analysis and evaluation, and visualization of results. The morphological analyzer is mainly used in word segmentation to segment the input text into words.

In this study, the questionnaire is written in Japanese language. Free software WordCloud (Created by Andreas Mueller) and KH coder are used for quantitative analysis of the text data. Co-occurrence network, self-organizing map (SOM), and word clouds are used to plot and cluster statistical analysis results. The characteristics of the three analysis methods are explained as follows.

- Co-occurrence Network.

In text mining, co-occurrence network is the most powerful analysis method, which is intuitive and easy to understand. If there is co-occurrence or association between the extracted words, they are connected by a line. The thickness of the connector line represents the strength of co-occurrence. Additionally, the size of the nodes represents the word frequency. 


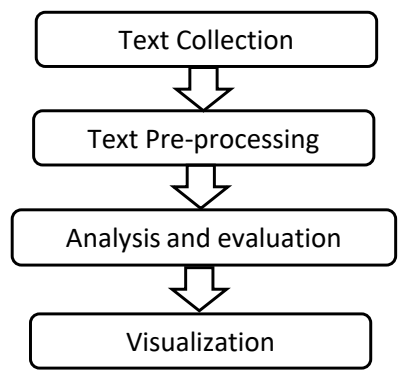

Figure 1. Basic process of text mining.

- Self-Organizing Map (SOM)

Self-organizing map is an artificial neural network, which can map the input data to any dimension (the two-dimensional plane in this study) by unsupervised learning. In the created SOM of the extracted words, words with similar meanings are automatically placed close to each other, and each feature group is color-coded for easy understanding.

- Word Clouds (https://amueller.github.io/word_cloud/)

Word clouds are a method for visually presenting the importance and frequency of extracted words with font size or color. Frequently used keywords are highlighted in larger text to identify trends and patterns of text.

\subsection{Analysis of Impression of Japanese, Chinese, and Korean Traditional Dances with Text Mining}

This study analyzed descriptive data obtained from a questionnaire about Japanese, Chinese, and Korean traditional dances. The questionnaire was conducted in classrooms at A and B universities for 90 minutes. Participants were asked to write about their impressions after they investigated and appreciated these dances on the Internet in class.

\subsubsection{Participants}

The participants were 254 undergraduates (Mean age: 19.57, SD: 1.12) including 152 male (60\%) and 102 female (40\%) students (Figure 2). Among them were 55 people with experiences of dance. Eighteen male students (12\%) had experience and 39 female students (38\%) had experience. The age range was from 18 to 24 and its distribution is shown in Figure 3.

\subsubsection{Open-Ended Question List}

This study used descriptions obtained from a questionnaire composed of the three items below.

(Q1) Please describe your impression and thought freely after you have finished observing the Japanese dances and watched videos of them.

(Q2) Please describe your impressions and thoughts freely after you have finished observing the Chinese dances and watched videos of them.

(Q3) Please describe your impressions and thoughts freely after you have finished observing the Korean dances and watched videos of them. 


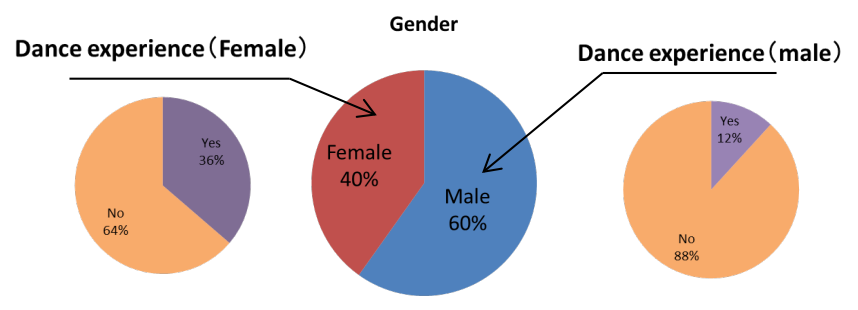

Figure 2. Distribution of participants' gender and experiences of dance.

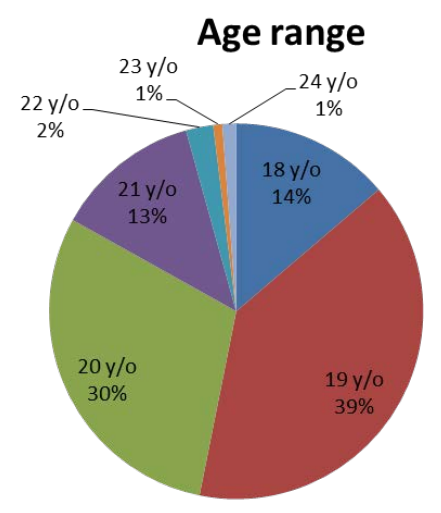

Figure 3. Distribution of participants' age range.

\section{Results}

The participants described their impressions and thoughts freely after observing the dances in each country and watching videos of them on the internet $(\mathrm{Q} 1, \mathrm{Q} 2$, and Q3). Appearance frequency of words in their answers to Q1 (Japanese dances), Q2 (Chinese dances), and Q3 (Korean dances) was respectively calculated and the top 10 of the appearance frequency in each question is shown in Table 1.

Looking at the result of the common terms shown in Table 1, the terms "movement", "Japan", and "dance" are often and mutually used for the dances of each country. For the differences between each country, the following terms can be cited: "beautiful", "traditional", and "delicate" for Japanese dance, "costume", "gorgeous", and "intense" for Chinese dance, and "China", "costume", and "similar" for Korean dance.

\subsection{Impressions and Thoughts of Japanese Dances}

The appearance frequency of words in the descriptions about Japanese dances was visualized with Word cloud (Figure 4), SOM (Figure 5), and co-occurrence network (Figure 6).

According to the result of Japanese dance on WordCloud (Figure 4), terms such as "movement", "beautiful", "traditional", "delicate", "slow", and "laid-back" are large and of high importance. Furthermore, the term "kimono" can be seen related to costumes. 
Looking at the self-organizing map (Figure 5), the term "movement" is located at the bottom right. Along with it, other terms such as "delicate", "graceful", "calm", "impression", and "image" are also located in the blue area at the bottom right of the map.

Looking at the co-occurrence network (Figure 6), the terms "movement" and "delicate" can be seen as related.

Table 1. Impression and thought of dances in each country.

\begin{tabular}{|c|c|c|c|c|c|}
\hline \multicolumn{2}{|c|}{ Japanese Dances (Q1) } & \multicolumn{2}{|c|}{ Chinese Dances (Q3) } & \multicolumn{2}{|c|}{ Korean Dances (Q3) } \\
\hline $\begin{array}{l}\text { Extracted } \\
\text { Words }\end{array}$ & $\begin{array}{l}\text { Appearance } \\
\text { Frequency }\end{array}$ & $\begin{array}{l}\text { Extracted } \\
\text { Words }\end{array}$ & $\begin{array}{l}\text { Appearance } \\
\text { Frequency }\end{array}$ & $\begin{array}{l}\text { Extracted } \\
\text { Words }\end{array}$ & $\begin{array}{c}\text { Appearance } \\
\text { Frequency }\end{array}$ \\
\hline $\begin{array}{l}\text { Movement } \\
\text { (動き) }\end{array}$ & 70 & $\begin{array}{l}\text { Japan } \\
\text { (日本) }\end{array}$ & 75 & $\begin{array}{l}\text { Japan } \\
\text { (日本) }\end{array}$ & 58 \\
\hline $\begin{array}{l}\text { Think } \\
\text { (思う) }\end{array}$ & 67 & $\begin{array}{l}\text { Think } \\
\text { (思う) }\end{array}$ & 60 & $\begin{array}{l}\text { Think } \\
\text { (思う) }\end{array}$ & 54 \\
\hline $\begin{array}{c}\text { Feel } \\
\text { (感じる) }\end{array}$ & 61 & $\begin{array}{l}\text { Movement } \\
\text { (動き) }\end{array}$ & 52 & $\begin{array}{l}\text { China } \\
\text { (中国) }\end{array}$ & 48 \\
\hline $\begin{array}{l}\text { Japan } \\
\text { (日本) }\end{array}$ & 54 & $\begin{array}{l}\text { Dance } \\
\text { (舞踊) }\end{array}$ & 52 & $\begin{array}{l}\text { Costume } \\
\text { (衣装) }\end{array}$ & 47 \\
\hline $\begin{array}{l}\text { Dance } \\
\text { (舞踊) }\end{array}$ & 51 & $\begin{array}{c}\text { Feel } \\
\text { (感じる) }\end{array}$ & 51 & $\begin{array}{l}\text { Dance } \\
\text { (舞踊) }\end{array}$ & 45 \\
\hline $\begin{array}{l}\text { Impression } \\
\text { (印象) }\end{array}$ & 34 & $\begin{array}{l}\text { China } \\
\text { (中国) }\end{array}$ & 34 & $\begin{array}{l}\text { Impression } \\
\text { (印象) }\end{array}$ & 42 \\
\hline $\begin{array}{l}\text { Beautiful } \\
\text { (美しい) }\end{array}$ & 33 & $\begin{array}{l}\text { Impression } \\
\text { (印象) }\end{array}$ & 32 & $\begin{array}{l}\text { Movement } \\
\text { (動き) }\end{array}$ & 40 \\
\hline $\begin{array}{l}\text { Tradition } \\
\text { (伝統) }\end{array}$ & 26 & $\begin{array}{l}\text { Costume } \\
\text { (衣装) }\end{array}$ & 29 & $\begin{array}{l}\text { Korea } \\
\text { (韓国) }\end{array}$ & 28 \\
\hline $\begin{array}{l}\text { Feeling } \\
\text { (感じ) }\end{array}$ & 23 & $\begin{array}{c}\text { Flamboyant } \\
\text { (華やか) }\end{array}$ & 28 & $\begin{array}{c}\text { Feel } \\
\text { (感じる) }\end{array}$ & 27 \\
\hline $\begin{array}{l}\text { Delicate } \\
\text { (繊細) }\end{array}$ & 20 & $\begin{array}{l}\text { Intense } \\
\text { (激しい) }\end{array}$ & 25 & $\begin{array}{c}\text { Resemble } \\
\text { (似る) }\end{array}$ & 27 \\
\hline
\end{tabular}

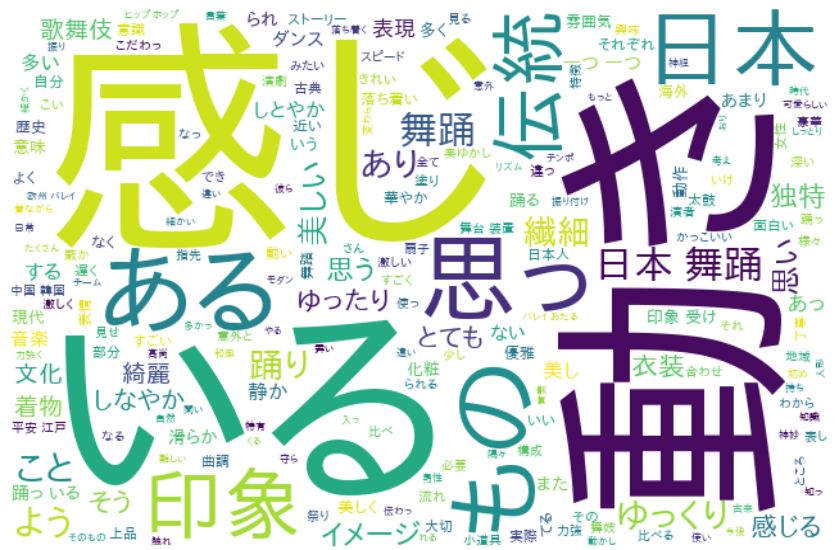

Figure 4. Word cloud of words in descriptions about Japanese dances. 


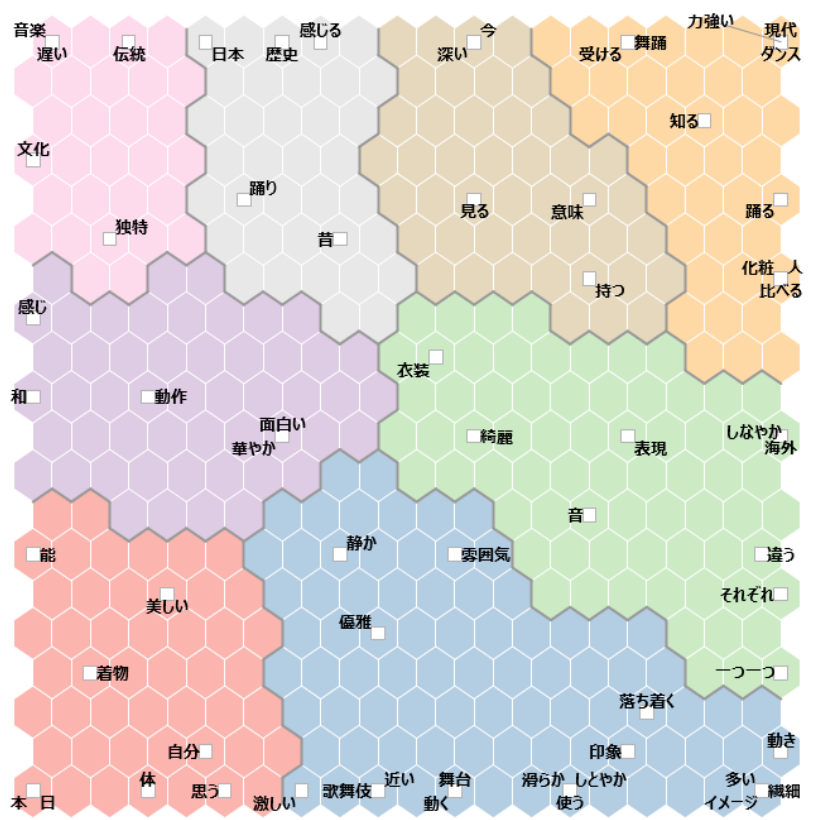

Figure 5. SOM of words in descriptions about Japanese dances.

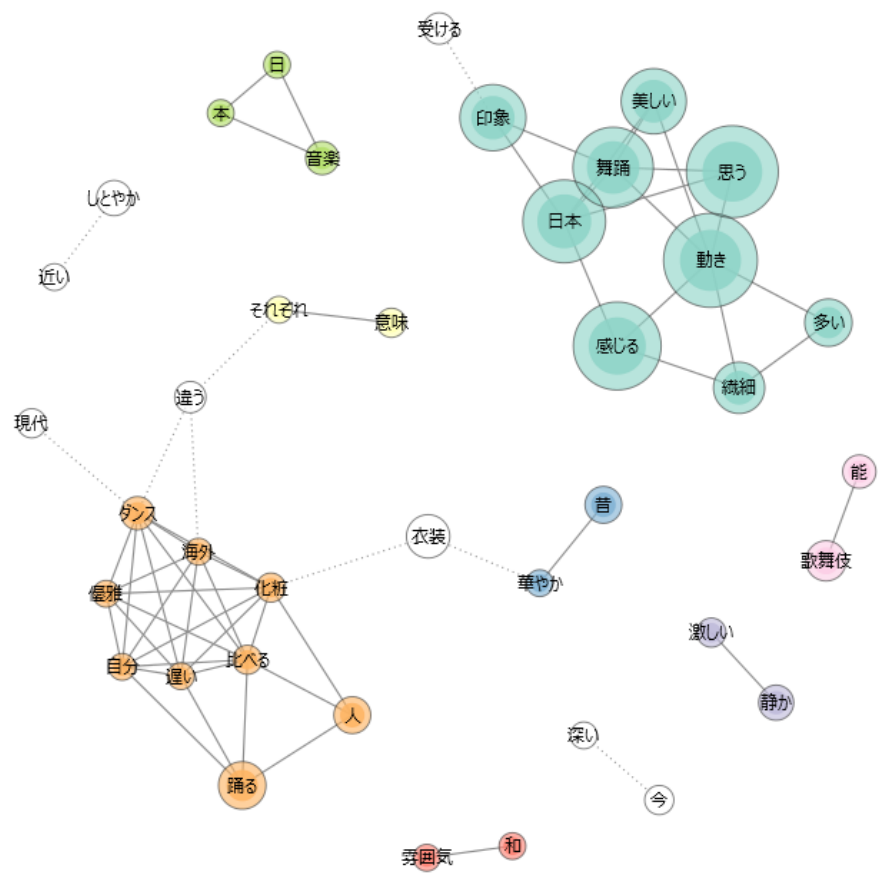

Figure 6. Co-occurrence network of words in descriptions about Japanese dances.

\subsection{Impressions and Thoughts of Chinese Dances}

The appearance frequency of words in the descriptions about Chinese dances was visualized with Word cloud (Figure 7), SOM (Figure 8), and co-occurrence network (Figure 9).

According to the result of Chinese dance on WordCloud (Figure 7), terms such as "movement", "costumes", "gorgeous", "intense", "vivid", and "flashy" 
are large and of high importance. Furthermore, the term "dress" can be seen related to costumes.

Looking at the self-organizing map (Figure 8), the term "movement" is located at the bottom right. Along with it, other terms such as "intense" and "sentiment" are also located in the green area at the bottom right of the map. Looking at the co-occurrence network (Figure 9), the terms "movement" and "intense" and the terms "intense" and "sentiment" can be seen as related.

\subsection{Impressions and Thoughts of Korean Dances}

The appearance frequency of words in the descriptions about Chinese dances was visualized with Word cloud (Figure 10), SOM (Figure 11), and co-occurrence network (Figure 12).

According to the result of Korean dance on WordCloud (Figure 10), terms such as "movement", "costumes", "similar", "gorgeous", "vivid", "flashy", "slow", and "laid-back" are large and of high importance. Furthermore, the term "Chima Jeogori" can be seen related to costumes.

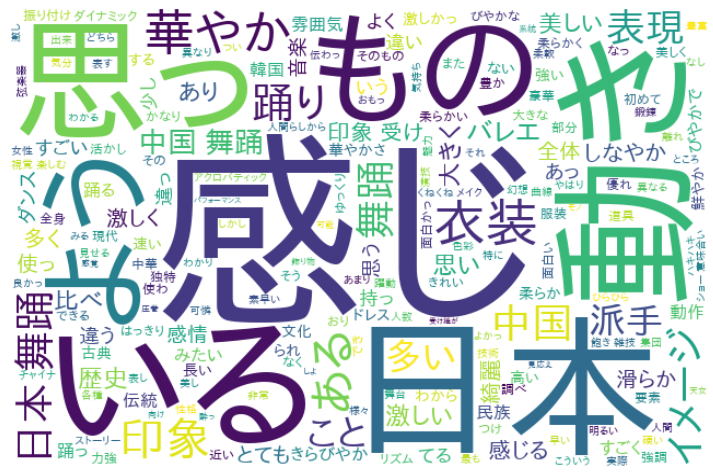

Figure 7. Word cloud of words in descriptions about Chinese dances.

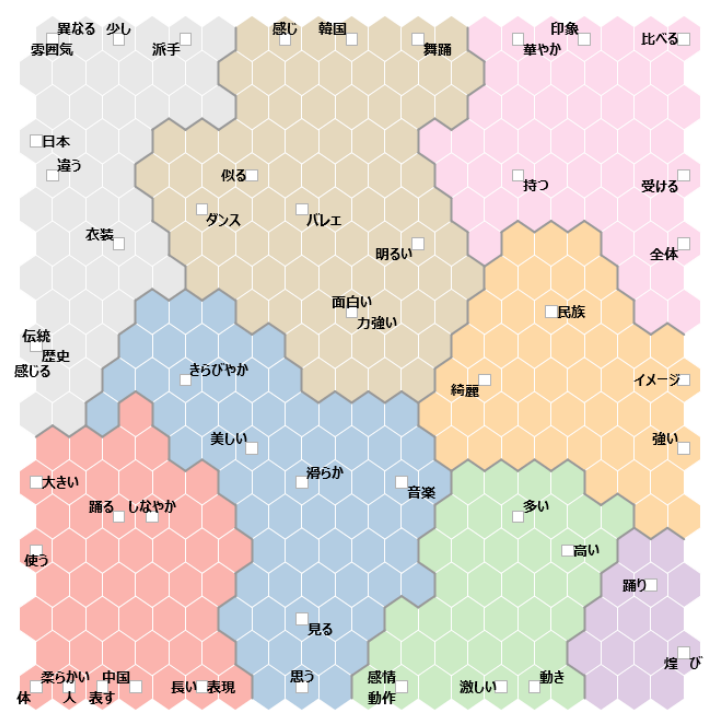

Figure 8. SOM of words in descriptions about Chinese dances. 


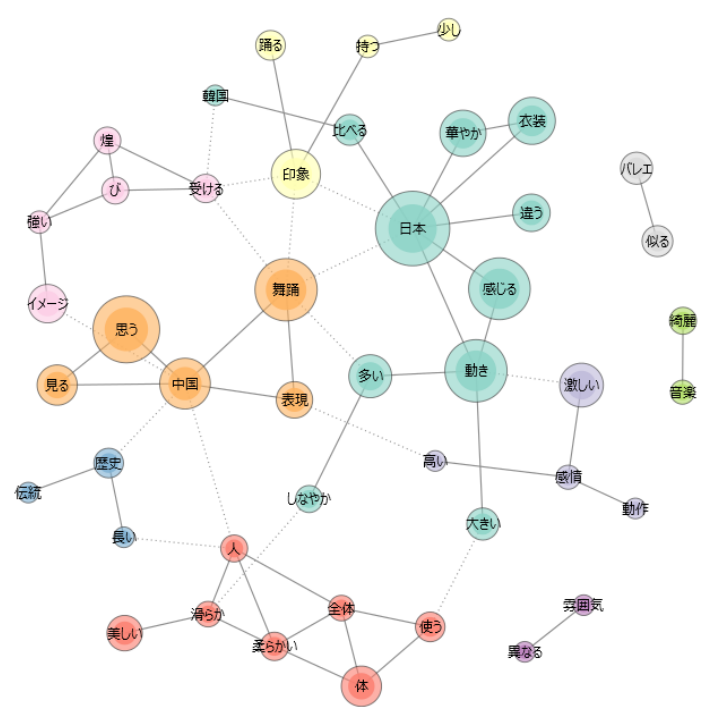

Figure 9. Co-occurrence network of words in descriptions about Chinese dances.

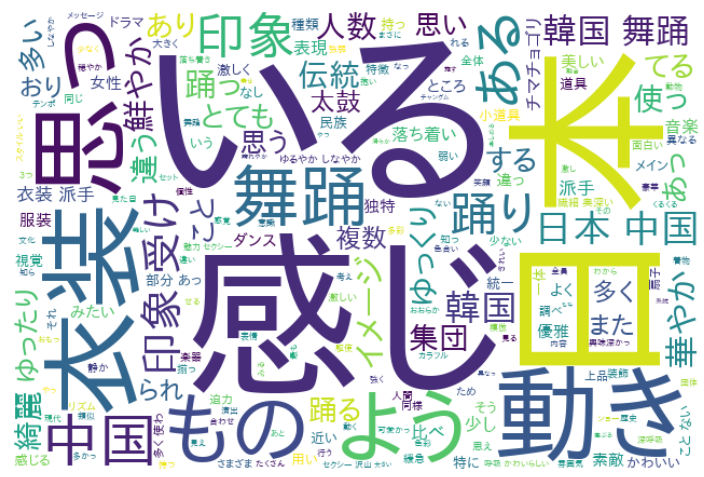

Figure 10. Word cloud of words in descriptions about Korean dances.

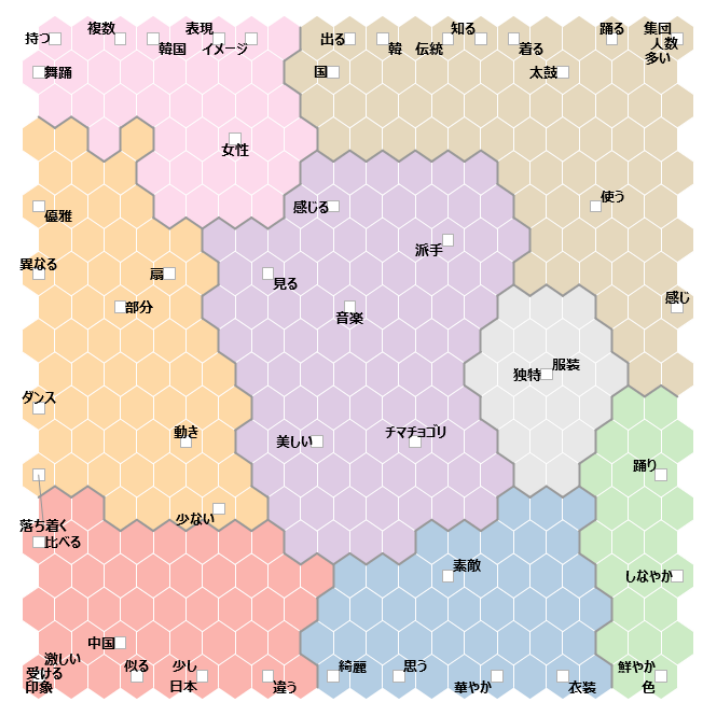

Figure 11. SOM of words in descriptions about Korean dances. 


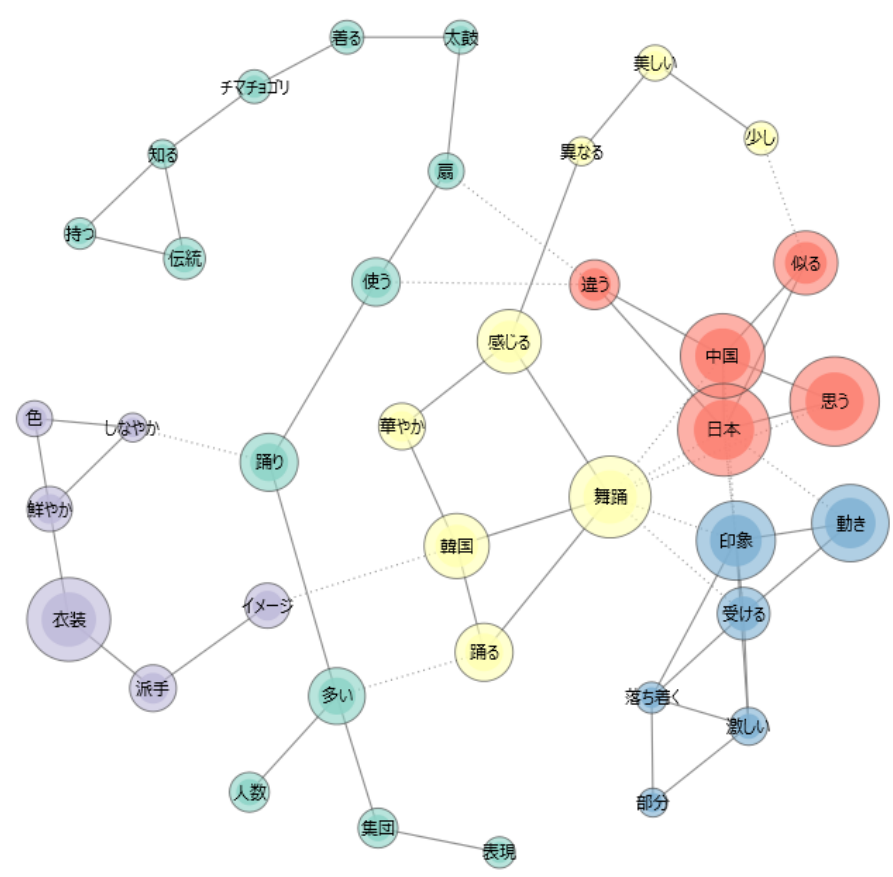

Figure 12. Co-occurrence network of words in descriptions about Korean dances.

Looking at the self-organizing map (Figure 11), the term "movement" is located on the left. Along with it, other terms such as "dance" and "fans" are also located in the orange area on the left of the map. Furthermore, an area with the term's "calm", "intense", "impression", "Japan", "China”, and "different" can be seen at the bottom left of the map.

Looking at the co-occurrence network (Figure 12), the terms "movement", "intense", and "calm" can be seen as related.

\section{Comparison of Impressions and Thoughts of Dances in Each Country}

\subsection{Discussion Based on the Frequency of Word Appearance of Impressions on Japanese, Chinese, and Korean Traditional Dances}

A list of frequently-used words in impressions and thoughts on the traditional dances of various countries was compiled, obtained from the results of openended questions to the university student participants of this study (Table 1). A frequently used word among participants for each type of dance was "movement". Participants noted that they could feel the movement even though they hadn't experienced the movement firsthand (Mizuguchi \& Kanosue, 2017). From this finding, it was confirmed that motor imagery occurs when watching the traditional dance of the target countries.

There are many different types of movements, so the word "movement" is vaguely defined. For instance, a calm gesture or posture can be considered a movement and may generate static motor imagery. On the other hand, a vigor- 
ous and dynamic motion is also considered movement but generates dynamic motor imagery. Taking the examples of the studies of Japanese traditional dance by Mito et al. $(2007,2008)$ and $\mathrm{Fu}$ (1997) mentioned above, the traditional dances of these countries have unique ways of conveying the same emotion. There are differences in the movement characteristics, so it is necessary to take a closer look at the characteristics of the dances and the impressions felt by the viewers in order to determine what kind of movement image was created.

Looking at the words used to describe each country's dance individually, the words that are most frequently used to describe the Japanese traditional dance are "beautiful", "traditional", "delicate". Those most frequently used to describe the Chinese traditional dance are "costume", "gorgeous", and "intense". Those most frequently used to describe the Korean traditional dance are "costume" and "similar". Participants' responses indicate that Japanese traditional dance leaves a beautiful and delicate impression, indicating that it has strong imagery as their traditional culture. The costumes of both Chinese and Korean traditional dances attract more attention, with the Chinese dance eliciting more "gorgeous" and "intense" impressions and the Korean dance may be considered to share common traits with those of the other countries.

\subsection{Discussion Based on the Analysis of Frequently Associated Words in the Impressions of Japanese, Chinese, and Korean Traditional Dances}

The results of the analysis of the participant's impressions were based on WordCloud, self-organizing maps, and co-occurrence networks (Figures 4-12). WordCloud (Figure 4, Figure 7, Figure 10) results show that the word "movement" has an important meaning in the descriptions of the traditional dances from Japan, China, and Korea. Also, a similar method based on the frequency of word appearance, the words "beautiful", "traditional", and "delicate" came up for Japanese dance, "costume", "gorgeous", and "intense" for Chinese dance, and "costume", and "similar" for Korean dance and have a relatively higher connection to movement than other words. Though not seen in the frequency of word appearance for Chinese or Korean dance, the words "slow" and "calm" were frequently used in describing the Japanese dance, and it was found that the Japanese dance gave the impression of calm and slow movements, more so than those from the other countries. Another feature is that both Chinese and Korean traditional dance give the viewer the impression of being "bright" or "flashy."

Masuko (1993) wrote the following on the features of Japanese traditional dance, "While western temporal art flows in rhythm, Japanese temporal art stops rather than flows. It can be said that Japanese dance is an art form that emphasizes how to stand still in the flow of time." This is consistent with the impression that Japanese students had on Japanese traditional dance compared to those of the other countries.

The words "slow" and "calm" were also found in WordCloud for the Korean traditional dance (Figure 7), and although these words are less prominent than 
the Japanese dance, it is clear that the Korean dance also gave the impression of calm and slow movements, revealing their differences from the Chinese dance.

Looking at the self-organizing map (Figure 5) and the co-occurrence network diagram (Figure 6), we could see the word "movement", which is commonly found in descriptions of traditional dances of Japan, China and Korea, is located at the lower right of the self-organizing map. The blue area occupying the lower right corner of the map is a cluster formed by words such as "subtle", "graceful", "calm", "impressive", and "imagery" along with "movement", which can be interpreted as a group of words related to the impression and imagery brought by the movement of the Japanese traditional dance. In the co-occurrence network diagram, the words "movement" and "subtle" are directly associated with one another, suggesting that the movement of the Japanese dance contributes primarily to the formation of the "subtle" impression.

In the Chinese dance, the word "movement" is located in the lower right of the self-organizing map (Figure 8) and forms the same cluster with words such as "intense" and "emotional". These words refer to the intense emotions conveyed by the movements of the Chinese dance. In the co-occurrence network diagram (Figure 9), there is a connection between the word "movement" and "intense", and between the words "intense" and "emotion", suggesting that the intensity of the Chinese dance plays an important role in conveying a specific emotion to the viewers.

In the Korean dance, the word "movement" is located at the left of the self-organizing map (Figure 11) and forms the same cluster with words such as "dance" and "fan". These words seem to focus on the visual aspects, such as the movements seen in Korean dances and the fans used in the dance. Words such as "calm," "intense," and "impressive" form the same cluster at the bottom left of the map, and this cluster also includes words such as "Japan," "China," and "different." This cluster shows the differences between the impression made by the Korean dance with those made by the Japanese and Chinese dances. Based on the co-occurrence network diagram (Figure 12), the words "intense" and "calm" are related, and these words form an indirect network with "movement". Although the WordCloud showed the slow-moving nature of the Korean dance, it can be inferred that viewers could notice the conflicting nature of the static and dynamic aspects of the Korean dance that gave both the impressions of "intense" and "calm" from the co-occurrence network.

In addition to "movement", other distinctive terms in each of the dances are "Kimono" in Japanese dance, "dress" in Chinese dance, and "Chima Jeogori" in Korean dance (Figure 4, Figure 7, Figure 10). In particular, in Chinese and Korean dance, the term "costume" is often mentioned. Based on the results of WordCloud (Figure 4, Figure 7, Figure 10), the word "costume" is more prominent in the Korean dance compared to Japanese dance, and words such as "gorgeous" and "flashy" are prominent in the Chinese dance. It can be inferred that the participants of the questionnaire felt that the Chinese and Korean dances were flashier than the Japanese dance. 


\subsection{Conclusion Based on the Impressions of the Japanese, Chinese, and Korean Traditional Dances}

From the above results, based on the frequency of appearance, WordCloud, self-organizing map, and co-occurrence network diagram (Table 1, Figures 4-12), it can be presumed that the properties that influence the impression of the three countries' dances can be classified into "movement" and "appearance (visually-effective)". In terms of "movement", the Japanese dance gives the impression of a calm and peaceful dance, the Chinese dance gives the impression of an active dance, and the Korean dance gives the impression of something in-between. When classified by "appearance properties", it seems that the Japanese dance has a gorgeous yet tranquil image, whereas the Chinese and Korean dances leave a flashier impression.

These two characteristics seem to overlap and greatly affect the impression of the traditional dances. The Japanese dance gives a calm impression, the Chinese dance gives a dynamic impression, and Korean dance gives a gorgeous impression to the viewers.

A study by Tsuda \& Kusumoto (2015) that used physiological indices showed that viewing traditional dances has a psychological effect on the viewers. Similarly, the results of this study show that by considering the characteristics of the psychological effects of the three countries' traditional dances, calm and static images were more often recalled after watching the Japanese dance, whereas dynamic, bright, and gorgeous images were more often recalled after watching the Chinese and Korean dances.

From the above, it can be inferred that the psychological effects of the three countries' traditional dances are that the viewing of the Japanese dance may lead to calming the viewer's mood and reducing the feeling of excitement. The viewing of the Chinese and Korean dances may lift the viewer's mood and stimulate mental and physical conditions.

Comparing Chinese and Korean dance, their difference lies in how Chinese emphasizes intensity whereas Korean emphasizes costume, which symbolizes the external (Table 1, Figure 7, Figure 10). This suggests that Chinese dance is more probable to affect physical activities as it gives a more dynamic impression, while Korean dance is more likely to affect one's mood because its costumes give a bright impression. As a way of describing the impressions of the seven types of movements of traditional dance on viewers as described by Matsumoto (1987), the Chinese dance is more likely to affect the physical sensation because it gives a more "vibrant" impression and the Korean dance is more likely to affect the mood because it gives the "fun" impression.

Dance therapy makes use of dance in mental health fields as part of the subjects' treatment. However, according to Ito \& Shirai (2015), watching dance performances can be thought to also contribute effects similar to those of psychotherapy, such as dance therapy-the aesthetic experience gained does not only indicate the understanding of the art, but also serves as an act of a deep and 
moving experience, which can then be expected to stimulate expressive activities.

In a study by Naito (2006) about the changes in emotions after listening to music, it was reported that regardless of the rhythm and tempo of the music, a specific degree of stress-relieving effect was observed. However, listening to slow music resulted in a less active mood.

In this case, a property shared by the traditional dances in this study is how they can be applied to a wide range of subjects because the target age is broad and it creates a particular cathartic effect. In particular, since Japanese dance is thought to have the effects of calming the mood and relaxing the mind and body, it can be applied to therapy subjects with high anxiety, those who are in a nervous state, as well as those in a slightly overactive or hyperactive state. On the other hand, since the Chinese and Korean dances are thought to encourage physical activities, they can be used for subjects with physical limitations or functional decline. Broadly speaking, such subjects include the elderly, dementia patients in the psychiatric field, and paralyzed patients in the rehabilitation field.

In such a case, dance appreciation is its applicability for the elderly who are bedridden and tend to fall into a state of disuse, or those who have accelerated physical decline and have difficulty to move freely. In addition, since the cognitive functions gradually decrease when a subject develops dementia, incorporating activities that stimulate the five senses is believed to prevent such functional deterioration.

Since watching traditional dances can stimulate the mind visually and through sound and movement, for patients who have difficulty in moving their bodies it is considered an effective way to prevent the acceleration of functional deterioration. In particular, with its strong "intensity", Chinese dance can provide patients stronger kinesthetic stimuli. Likewise, with its intense color-induced stimuli that arise from the use of "costumes" and ornaments, Korean dance is considered to provide more visual stimuli to the patients. Conversely, while the Chinese and Korean dances are able to promote the activities of the mind and body, the application of the Japanese dance for the elderly may, for example, be related to their memories of the past from the traditional kimonos worn by the dancer. By doing that, the effect of stimulating the memory function of the patients may be achieved.

In this manner, when conducting an approach with the psychotherapeutic effects of watching the traditional dances of the three countries, it is important to match the functional condition of the participants that are going to be addressed with the dance that is going to be shown. These kinds of dances are not only enjoyable but also therapeutic

\section{Conclusion}

In this manuscript, we conducted text mining (quantitative text analysis) using the WordCloud and $\mathrm{KH}$ Coder on the free description column of the questionnaire for participants before and after viewing the traditional dances of Japan, 
China, and Korea. In this study, by not only focusing on the word appearance frequency but also based on the analyzes of the results of WordCloud, self-organizing maps, and co-occurrence networks, and the free description of the impressions of the dances, we have further clarified that the characteristics of the dances of the three countries and the characteristics of psychological influence on viewers are composed of two axes, which are "movement" and "appearance features" and showed the possibility of using traditional dance viewing in the field of mental health care. An important advantage of introducing traditional dance viewing in the field of mental health care is that it can be applied to subjects with limited physical functions, and thus, it can be expected to be useful in the medical and health preservation fields. As the features of the psychological effects of the dances, it seems that the Japanese dance is able to calm the mood and reduce anxiety, whereas the Chinese and Korean dances are able to promote physical activities.

In this study, the participants were asked to investigate and appreciate the traditional dances themselves on the Internet. Therefore, participants might have obtained different knowledge and watched different videos of the traditional dances. One future task will be to clarify relationships between various characteristics of each traditional dance such as movement, music, and costumes and their impressions through surveys using common videos of each traditional dance.

\section{Conflicts of Interest}

The authors declare no conflicts of interest regarding the publication of this paper.

\section{References}

Abe, H., Hirano, S., \& Tsumoto, S. (2007). Evaluation Temporal Models Based on Association Mining from Medical Documents. Japan Journal of Medical Informatics, 27, 33-38. (In Japanese)

Andreas Mueller. https://amueller.github.io/word_cloud

Berry, M. W. (2004). Automatic Discovery of Similar Words. In Survey of Text Mining: Clustering, Classification and Retrieval (pp. 24-43). New York: Springer Verlag.

Camurri, A., Lagerlöf, I., \& Volpe, G. (2003). Recognizing Emotion from Dance Movement: Comparison of Spectator Recognition and Automated Techniques. International Journal of Human-Computer Studies, 59, 213-225. https://doi.org/10.1016/S1071-5819(03)00050-8

Chang, H. M., Huang, E. W., Hou, I. C., Liu, H. Y., Li, F. S., \& Chiou, S. F. (2019). Using a Text Mining Approach to Explore the Recording Quality of a Nursing Record System. The Journal of Nursing Research, 27, 1-8. https://doi.org/10.1097/jnr.0000000000000295

Daigo, E., Kimura, K., \& Sakuno, S. (2019). The Effects of Ballet Appreciation Programs on the Appreciation Ability of Audiences: An Attempt to Structure Sports Appreciation Behavior. Japanese Journal of Management for Physical Education and Sports, 32, 25-47. (In Japanese) 
Fu, T. (1997). Head Expression in Chinese Dance: Focusing on Peking Opera. Choreologia, 20, 74 .

Fujii, A. (2017). Survey of Text Mining Studies [Project Report]. Ishikawa: Japan Advanced Institute of Science and Technology. (In Japanese) https://dspace.jaist.ac.jp/dspace/bitstream/10119/14183/5/paper.pdf

Higuchi, K. (2016). A Two-Step Approach to Quantitative Content Analysis: KH Coder Tutorial Using Anne of Green Gables (Part I). Ritsumeikan Social Science Review, 52, 77-91. http://www.ritsumei.ac.jp/file.jsp?id=325881

Higuchi, K. (2017). A Two-Step Approach to Quantitative Content Analysis: KH Coder Tutorial Using Anne of Green Gables (Part II). Ritsumeikan Social Science Review, 53, 137-147. http://www.ritsumei.ac.jp/file.jsp?id=346128

Ito, M., \& Shirai, A. (2015). A Study Regarding Appreciation of Dance Performance: How the P.E. Students Assimilate a Dance Performance by People with Intellectual Disabilities and Their Families. Research Journal of Japan Association of Physical Education for Women, 31, 19-33. (In Japanese) https://doi.org/10.15561/20755279.2015.0405

Kimura, M., Hurukawa, H., Tsukamoto, H., Tasaki, H., Kuga, M., Ohkura, M., \& Tsuchiya, M. (2005). Analysis of Questionnaires Regarding Safety of Medicine Use, Application of Text Mining to Free Description Questionnaires. The Japanese Journal of Ergonomics, 41, 297-305. (In Japanese) https://doi.org/10.5100/jje.41.297

Kinjo, M. (1973). A Study of Cognitive Structure of Dance Appreciation [1-2]-With Semantic Differential Method. Bulletin of College of Education, University of the Ryukyus, 2, 27-50. (In Japanese)

Masuko, H. (1993). The Rhythm and Pause of Japanese Classic Dance: Esthetics of Traditional Arts in Japan. Yamano Aesthetic Archives, 1, 53-60. (In Japanese)

Matsumoto, C. (1987). Dance Research: Problem Situation and Learning of Problem Solving II-Qualities of Movements and Feeling Values. Research Journal of JAPEW, 87, 53-89. (In Japanese)

Mito, Y., Shinoda, Y., Kawakami, H., \& Marushige, M. (2007). Relations between of Impressions of Audiences and Motional Expressions of Nihon Buyo-Japanese Traditional Dance. In The 5th Conference of the Japanese Society for Cognitive (pp. 23-27). (In Japanese)

Mito, Y., Shinoda, Y., Kawakami, H., \& Marushige, M. (2008). Characteristics of Each School of Nihon Buyo. In Proceedings of Jinmoncom 2008 (pp. 269-274). (In Japanese)

Mizuguchi, N., \& Kanosue, K. (2017). Motor Imagery and Performance. Journal of the Society of Instrument and Control Engineers, 56, 568-572. (In Japanese)

Naito, M. (2006). The Study of Relationship between Listening to Music and Mood ChangeMusical Tempo and Melody, Preference Music Influence on a Mood Scale and Relaxation State. Nihon University GSSC Journal: The Bulletin of the Graduate School of Social and Cultural Studies, Nihon University, 7, 443-452. (In Japanese)

Nishida, J., Hashimoto, K., Kiuchi, A., Tanimoto, H., Fukuchi, T., Kamijo, T., Onizawa, Y., Nakao, H., Kiyama, K., Arai, Y., \& Ogawa, M. (2015). Extraction of the Perceived Benefits of University Physical Education Classes by Text Mining: Differences in Sex and Exercise Habits among the Categories of Perceived Benefits. Osaka Research Journal of Physical Education, 60, 27-39. (In Japanese)

https://doi.org/10.5432/jjpehss.14049

Nyström, K., \& Lauritzen, S. O. (2005). Expressive Bodies: Demented Persons' Communication in a Dance Therapy Context. Health, 9, 297-317.

https://doi.org/10.1177/1363459305052902

Okabe, T., Yshikawa, T., \& Furuhashi, T. (2006). Proposal of Multi-Connected Hierar- 
chical Text Mining Method for Medical Incident Reports. In 22nd Fuzzy System Symposium. Proceedings of the Fuzzy System Symposium (Vol. 22, pp. 211-214). (In Japanese)

Park, K., Hirayama, M., Terayama, Y., Zushi, M., \& Yonezawa, M. (2017). A Text Mining analysis of the Dance Impressions of College Students in Dance Classes: Considering How Dance Classes in College Level Physical Education Should Be. Bulletin of Sport and Physical Education Center, University of Tsukuba, 39, 29-44.

Sakata, M., Shiba, M., \& Tadenuma, M. (2002). Recognition of KANSEI Information on Body Expression: Analysis of Estimation of Impression and Eye Movement. ITE Technical Report, 26, 9-12. (In Japanese)

Santos, A. D., Tang, L. M., Loke, L., \& Maldonado, R. M. (2018). You Are Off the Beat: Is Accelerometer Data Enough for Measuring Dance Rhythm? In MOCO'18 (pp. 1-8). https://doi.org/10.1145/3212721.3212724

Sawada, M., Suda, K., \& Ishii, M. (2003). Expression of Emotions in Dance: Relation between Arm Movement Characteristics and Emotion. Perceptual and Motor Skills, 97, 697-708. (In Japanese) https://doi.org/10.2466/pms.2003.97.3.697

Shikanai, N., Sawada, M., \& Ishii, M. (2013). Development of the Movements Impressions Emotions Model: Evaluation of Movements and Impressions Related to the Perception of Emotions in Dance. Journal of Nonverbal Behavior, 37, 107-121. (In Japanese) https://doi.org/10.1007/s10919-013-0148-y

Simon, K., Lawrence, C., David, M., Christopher, B., Chris, M. M., Gholamreza, H., Ingrid, Z., \& Karin, V. (2016). Text Mining Electronic Hospital Records to Automatically Classify Admissions against Disease: Measuring the Impact of Linking Data Sources. Journal of Biomedical Informatics, 64, 158-167.

https://doi.org/10.1016/j.jbi.2016.10.008

Swierczynska-Kaczor, U., \& Wachowicz, J. (2017). Understanding the Film Audience-Providing Insight into the Viewer's Experience from Text Mining and Manual Text Analysis of Online Film Reviews. Problemy Zarz Ėdzania, 15, 177-193. https://doi.org/10.7172/1644-9584.71.12

Tadaki, K., \& Abe, A. (2019). The Influence of Story Creating Activities While Appreciating Abstract Artworks. In The 33rd Annual Conference of the Japanese Society for Artificial Intelligence (pp. 126-135). Berlin: Springer. (In Japanese) https://doi.org/10.1007/978-3-030-39878-1_12

Tanaka, Y. (2018). What Do Art Novices See in Paintings? An Exploratory Study on Conversation in Appreciation of Representational Paintings. Cognitive Studies, 25, 26-49. (In Japanese)

Tsuda, H., \& Kusumoto, Y. (2015). A Study of the Influence of Creativity on Dance Learning-A Psychophysiological Approach on SRR Reaction Using Music and Visual Stimuli. Bulletin of Nippon College of Physical Education, 44, 67-76. (In Japanese)

Tsukamoto, J., Harada, J., Inosaki, Y., Nishi, Y., Maeda, M., Shiba, M., \& Kodaka, N. (2003). Examination of Basic Emotions from the Perspective of Dance Movement. Choreologia, 27, 62. (In Japanese)

Tsuruta, S., Morioka, H., Woong, C., Sekiguchi, H., \& Hachimura, K. (2009). Generation and Evaluation of Emotional Body Motion for Virtual Dance Collaboration. The Journal of the Institute of Image Information and Television Engineers, 63, 1807-1814. (In Japanese) https://doi.org/10.3169/itej.63.1807

Wang, W. X., Feng, Y., \& Dai, W. Q. (2018). Topic Analysis of Online Reviews for Two Competitive Products Using Latent Dirichlet Allocation. Electronic Commerce Research and Applications, 29, 142-156. https://doi.org/10.1016/j.elerap.2018.04.003 
Yoo, M. (2007). Principal Concepts in the Aesthetics of Korean Traditional Dance. Society and Culture. Journal of the Socio-Cultural Research Institute, Ryukyu University, 9, 77-80.

Yue, N. (2017). A Brief Discussion on the Technical Skill Difference between Chinese Classical Dance and Western Dance. In 2017 International Conference on Humanities Science, Management and Education Technology (pp. 334-337).

https://doi.org/10.2991/hsmet-17.2017.69 